\title{
VALOR NUTRICIONAL DE QUEIJOS MINAS FRESCAIS CONVENCIONAIS E ORGÂNICO COMERCIALIZADOS NA ZONA SUL DO ESTADO DO RIO DE JANEIRO, RJ.
}

$\underline{\text { Ruan Soares Medeiros dos Santos }}{ }^{1}$ (ruan93@oi.com.br); Luciana Ribeiro Trajano Manhães²; Ellen Mayra Menezes Ayres;

\footnotetext{
${ }^{1}$ Programa de Pós-Graduação em Neurologia (PPGNEURO); Universidade Federal do Estado do Rio de Janeiro (UNIRIO).

${ }^{2}$ Docente da Escola de Nutrição; Universidade Federal do Estado do Rio de Janeiro (UNIRIO).

${ }^{3}$ Docente da Escola de Nutrição e do Programa de Pós-graduação em Alimentos e Nutrição; Universidade Federal do Estado do Rio de Janeiro (UNIRIO).
}

O queijo Minas frescal é um dos queijos mais populares e o terceiro tipo mais produzido no Brasil. Nas ultimas décadas, a fabricação do queijo minas frescal sofreu modificações, visando melhora na qualidade do produto, buscando-se a padronização e segurança microbiológica. Este trabalho teve como objetivo avaliar a composição centesimal de queijos do tipo minas frescal comercializados no Estado do Rio de Janeiro, entre lotes diferentes com 12 meses de intervalo de fabricação. Cinco amostras comerciais foram selecionadas (A, B, C, D e E). Foram avaliados os teores de umidade, resíduo mineral fixo (RMF), nitrogênio total e proteína bruta, fração lipídica e carboidrato (IAL, 2008), bem como o valor calórico obtido foi baseado no fator de Atwater. Os dados provenientes de todas as análises foram avaliados estatisticamente pela análise de variância e teste de Tukey ( $\mathrm{p}$ $0,05)$. No primeiro lote, a amostra $C$ apresentou maior teor de umidade $(67,30 \% \pm 1,08)$ e $\mathrm{RMF}$ $(3,57 \% \pm 1,84)$, quando comparada com as demais. As amostras A $(34,20 \mathrm{~g} \pm 0,21)$ e B $(33,90 \mathrm{~g} \pm$ $0,57)$ apresentaram maior teor de carboidrato, enquanto a amostra $\mathrm{E}(10,70 \mathrm{~g} \pm 0,32)$ o maior conteúdo proteico. O teor de lipídeos foi superior nas amostras D $(2,70 \mathrm{~g} \pm 0,09)$ e E $(2,72 \mathrm{~g} \pm 0,31)$, não havendo diferença significativa entre elas. A amostra A $(170,50 \mathrm{Kcal} \pm 1,90)$ apresentou o maior valor energético. No segundo lote, a amostra $E$ apresentou-se com maior umidade $(68,22 \% \pm$ $0,48), \operatorname{RMF}(3,15 \% \pm 0,38)$ e proteína $(11,26 \mathrm{~g} \pm 1,07)$, a amostra C com mais carboidrato $(41,48 \mathrm{~g}$ $\pm 0,40)$, e a amostra B com mais lipídeo $(5,06 \mathrm{~g} \pm 0,12)$. Com relação ao valor energético, as amostras B $(184,46 \mathrm{Kcal} \pm 3,40)$, C $(185,23 \mathrm{Kcal} \pm 1,75)$ e D $(178,64 \mathrm{Kcal} \pm 3,68)$ apresentaram valores superiores às demais, porém não destoaram estatisticamente entre si. Conclui-se que é importante uma padronização na cadeia produtiva para melhor controle entre todas as marcas comerciais, sobretudo nos aspectos nutricionais deste produto.

Palavras-chave: Composição Centesimal, Queijo Minas Frescal, Rio de Janeiro. 